\title{
Urinary Biomarkers for Kidney Disease in ATTR Amyloidosis
}

\author{
Rocha $A^{1 *}$, Bravo $F^{2}$, Beirão $I^{1,3,4}$, Vizcaíno $\mathrm{J}^{4,5}$, Oliveira $\mathrm{JC}^{2}$ and Lobato $\mathrm{L}^{1,3,4}$
}

${ }^{1}$ Department of Nephrology, St. Anthony Hospital, Central Hospital of Porto, Porto, Portugal ${ }^{2}$ Department of Clinical Chemistry, St. Anthony Hospital, Central Hospital of Porto, Porto, Portugal ${ }^{3}$ Unit Clinic Paramiloidose, St. Anthony Hospital, Central Hospital of Porto, Porto, Portugal

${ }^{4}$ UMIB, Institute of Biomedical Sciences Abel Salazar - ICBAS, University of Porto, Porto, Portugal

${ }^{5}$ Department of Pathology, St. Anthony Hospital, Central Hospital of Porto, Porto, Portugal

\begin{abstract}
Aim: The detection and prognosis of nephropathy in transthyretin amyloidosis depends on albuminuria and renal function. Knowing that urinary levels of alpha-1 microglobulin and beta- 2 microglobulin reflect tubular dysfunction while urinary alpha-2 macroglobulin implies glomerular damage, we decide investigate the diagnostic value of these markers in the patients with transthyretin amyloidosis.
\end{abstract}

Methods: Serum and urinary samples collected from 30 patients and 11 asymptomatic carriers were tested for alpha-1 microglobulin, beta-2 microglobulin, alpha-2 macroglobulin, albumin, creatinine and cystatin C.

Results: Pathological urinary alpha-1 microglobulin was detected in 17 patients, beta-2 microglobulin in 6 and alpha-2 macroglobulin in 5; 5 patients had albuminuria (mg/g creatinine) 30-300 and in 20 patients values $>300$ were present. Asymptomatic carriers did not present pathological excretion of these biomarkers and albuminuria was $>30$ in 1 individual. The excretion rates of alpha-1 microglobulin and beta- 2 microglobulin were positively correlated with albuminuria $(P<0.001)$, serum creatinine $(P<0.05)$ and cystatin $C(P<0.001)$. Urinary alpha-2 macroglobulin was almost exclusively found in the presence of albuminuria, although their levels do not correlate.

Conclusion: Urinary biomarkers emerge as a potential approach to detect renal disease but unexpectedly, urinary alpha-2 macroglobulin was not a marker of the severity of albuminuria.

Keywords: Transthyretin; Amyloid; Low molecular weight proteins; Kidney; Proximal tubules

\section{Introduction}

The Amyloidoses Associated with Transthyretin (ATTR) are autosomal-dominant diseases related to at least 100 different Transthyretin (TTR) mutations. The single amino-acid substitution of methionine for valine at position 30 is the most common [1]. Although this disorder was initially thought to follow a benign evolution concerning the kidney, it was later recognized that progression to EndStage Renal Disease (ESRD) occurs in up to 10 percent of patients as natural course of the disease [2]

The detection and prognosis of ATTR nephropathy depend on the presence of albuminuria and an elevated serum creatinine concentration. These are correlated with the amount of amyloid in the glomeruli, arterioles, and medium vessels. When amyloid is confined to the tubulointerstitium or vasculature, proteinuria is minimal and reduced Glomerular Filtration Rate (GFR) is the principal clinical manifestation. In some patients, proximal tubular epithelial cells contained reabsorption-like droplets TTR positive and Congo-red stain negative, but clinical expression of tubular dysfunction has not been described until now [2].

Conventional measurements of renal function, such as creatinine and BUN levels, are limited by several non-renal factors, including body weight and nutritional status, which are particularly relevant in this population. Of special note, increased concentrations of albuminuria among patients with a GFR $>60 \mathrm{ml} / \mathrm{min}$ (an area of weakness for serum creatinine and GFR), may define a higher risk patients to develop clinical nephropathy.

Specific urinary biomarkers for tubular and interstitial pathologic abnormalities are needed for early detection and timely treatment. Ideally, there should be early markers of nephropathy in initial stages of ATTR, even before neurological manifestations.
Although Orthotopic Liver Transplantation (OLT) is performed as a potential curative treatment, new strategies have been developed to treat Familial Amyloidotic Polyneuropathy (FAP) [3]. Tafamidis was approved for the treatment of ATTR in adult patients with stage 1 symptomatic polyneuropathy to delay peripheral neurologic impairment [4]. Several trials, some already completed and others recruiting participants, are evaluating new drugs [5]. Until now, trials did not clarify whether kidney disease is a criterion for excluding or adopting the use of a given drug. Most trials accept patients with evidence of neuropathy, some with cardiomyopathy but none of them have admitted patients with nephropathy as an isolated feature. It is questionable whether a patient with proteinuria, renal amyloid deposition identified as TTR and without other manifestations of disease would be a candidate for any future therapy.

In the past decades, several urinary proteins have been identified as early prognostic markers in different kidney diseases [6]. Beta-2Microglobulin (B2M) and Alpha-1-Microglobulin (A1M) are both low molecular weight proteins that are freely filtered by glomerulus, efficiently reabsorbed and catabolized by proximal tubule. No active tubular secretion or significant extra renal elimination occurs. Therefore, in the presence of renal dysfunction, B2M and A1M serum levels are increased when compared to those patients with normal

*Corresponding author: Ana Rocha, Department of Nephrology, St. Anthony Hospital, Central Hospital of Porto, Porto, Portugal; Tel: +351222077500; Fax: +351222053218; E-mail: acrisbraga@gmail.com

Received June 25, 2014; Accepted September 10, 2014; Published September 18,2014

Citation: Rocha A, Bravo F, Beirão I, Vizcaíno J, Oliveira JC, et al. (2014) Urinary Biomarkers for Kidney Disease in ATTR Amyloidosis. J Nephrol Ther 4: 181. doi:10.4172/2161-0959.1000181

Copyright: $\odot 2014$ Rocha A, et al. This is an open-access article distributed under the terms of the Creative Commons Attribution License, which permits unrestricted use, distribution, and reproduction in any medium, provided the original author and source are credited. 
renal function [7]. Alpha-2 Macroglobulin (A2M) is a tetrameric glycoprotein, produced in human plasma that has a molecular mass of $725 \mathrm{kDa}$ [8]. Urinary levels of A2M increase when glomerular leakage occurs and, consequently, can act as a marker of such impairment. The aim of this study was to evaluate urinary A1M, B2M and A2M as early markers of ATTR nephropathy and predictors of outcome of renal disease.

\section{Patients and Methods}

We evaluated a cohort of thirty patients and eleven asymptomatic gene carriers with the TTR V30M mutation. Information about demographics and clinical characteristics was collected. Age-at-onset of FAP was defined as the age of initial neurologic features.

Amyloid deposition was confirmed histologically in 24 patients; sections from formalin-fixed, paraffin-embedded biopsy specimens were stained with Congo red and viewed under cross-polarized light.

Patients who attended our clinic were followed by the same nephrological team. Diabetic patients and patients submitted to OLT, therapy with tafamidis or under any therapeutic clinical trial were excluded.

\section{Markers Measurements} taken.

On the day of the urine sample collection, blood samples were

Serum and urinary creatinine levels $(\mathrm{mg} / \mathrm{dL})$ were measured by a rate-blanked compensated Jaffé method on a Modular P analyzer (Roche Diagnostics, Mannheim, Germany). Urinary albumin levels $(\mathrm{mg})$ were measured with an automated immunoturbidimetric assay using the Cobas Integra 800 analyser (Roche Diagnostics, Mannheim, Germany). The amount of albuminuria was estimated by the albumin to creatinine ratio $(\mathrm{mg} / \mathrm{g})$. Albuminuria $<30 \mathrm{mg} / \mathrm{g}$ was considered normal.

Urinary B2M $(\mathrm{ng} / \mathrm{mL})$ was measured by a chemiluminescent immunometric assay using IMMULITE 2000 (Siemens Medical Solutions, Erlangen, Germany), whereas urinary A1M levels (mg/L) and urinary A2M $(\mathrm{mg} / \mathrm{L})$ were measured with nephelometry on a Siemens BNII nephelometer (Siemens Medical Solutions, Erlangen, Germany).

Urinary values of $\mathrm{A} 1 \mathrm{M}>12 \mathrm{mg} / \mathrm{L}, \mathrm{A} 2 \mathrm{M}>9.4 \mathrm{mg} / \mathrm{L}$ and $\mathrm{B} 2 \mathrm{M}>300$ $\mathrm{ng} / \mathrm{mL}$ were considered abnormal. These biomarkers were corrected for urinary creatinine.

The GFR was estimated by serum cystatin C (CysC) expressed in $\mathrm{mg} / \mathrm{dL}$. It was determined on a nephelometric analyzer (Behring Nephelometer 2; Paris La Défense Cedex, Paris, France) by means of particle-enhanced immunonephelometry (N latex CysC; Dade Behring, Marburg, Germany) after calibration and control. Cystatinestimated GFR was calculated according to Larsson formula: GFR = $77.239 \times \mathrm{CysC}^{-1.2623}[9]$.

The inflammatory state was evaluated by determination of C-reactive protein (CRP) (reference value $<5 \mathrm{mg} / \mathrm{L}$ ) and ferritin values (reference range 12.5-454 ng/mL). Pro-B-type natriuretic peptide (pro$\mathrm{BNP}$ ) concentration was measured in all subjects (reference value $<227$ $\mathrm{pg} / \mathrm{mL})$.

\section{Statistical Analysis}

Correlations were assessed by Spearman correlation coefficient test. The level of significance was considered to be $P<0.05$. Values are expressed as mean \pm standard deviation.

\section{Results}

Patients were $49.4 \pm 12.6$ years-old, 18 females and 12 males, who presented a neuropathy evolution of $5.0 \pm 4.4$ years. Asymptomatic gene carriers were $41.4 \pm 15$ years-old, 9 females and 2 males.

Twenty four patients were biopsied and deposition of amyloid was demonstrated in 21: 15 (71.4\%) on salivary gland biopsy, 4 (19\%) on renal biopsy (Figure 1), 1 (4.8\%) on myocardial tissue biopsy and 1 (4.8\%) from peripheral nerve tissue biopsy.

The laboratory data is summarized in Tables 1, 2 and 3. Eleven patients showed overt renal failure, with 5 of them progressing to dialysis. None of the patients showed glycosuria.

B2M was detected in all asymptomatic gene carriers with a mean value of $62.7 \mathrm{ng} / \mathrm{mL}$ (range 16.1 to $121 \mathrm{ng} / \mathrm{mL}$ ). Also, A1M was present in 4 subjects with a mean value of $9.7 \mathrm{mg} / \mathrm{L}$ (range $8.5-12 \mathrm{mg} / \mathrm{L}$ ) and $\mathrm{A} 2 \mathrm{M}$ was only detected in one individual with a value of $3.34 \mathrm{mg} / \mathrm{L}$. All values were on the reference range.

Pathological urinary $\mathrm{A} 1 \mathrm{M}, \mathrm{B} 2 \mathrm{M}$ and $\mathrm{A} 2 \mathrm{M}$ levels were detected in 17, 6 and 5 patients respectively. However, none of the asymptomatic gene carriers showed such abnormal excretion.

A1M concentration was $45.2 \pm 41.3 \mathrm{mg} / \mathrm{L}$ in all 30 patients. Medium B2M and A2M concentration were $22592.8 \pm 27047.6 \mathrm{ng} / \mathrm{mL}$ and 28.6 $\pm 34.3 \mathrm{mg} / \mathrm{L}$, respectively. The values corrected for urinary creatinine were $86 \pm 110 \mathrm{mg} / \mathrm{L}, 54759 \pm 63665 \mathrm{ng} / \mathrm{mL}$ and $56 \pm 75 \mathrm{mg} / \mathrm{L}$ for each marker respectively.

Six patients had albuminuria $<30 \mathrm{mg} / \mathrm{g}, 4$ between 30 and $300 \mathrm{mg} / \mathrm{g}$ and $20>300 \mathrm{mg} / \mathrm{g}$. Among normoalbuminuric patients we found one with urinary pathological levels of $\mathrm{A} 2 \mathrm{M}$ and $\mathrm{A} 1 \mathrm{M}$ and another with abnormal B2M levels. Among 14 patients who evolved to ESRD, 5 presented simultaneous detection of $\mathrm{A} 1 \mathrm{M}$ and $\mathrm{A} 2 \mathrm{M}$.

$\mathrm{A} 1 \mathrm{M}$ and B2M, were positively correlated with albuminuria, serum creatinine and cystatin C (Table 4) in all patients. A2M was almost exclusively found in the presence of albuminuria $>30 \mathrm{mg} / \mathrm{g}$, although their levels do not correlate with the severity of albuminuria.

There were no significant correlations between urinary levels of $\mathrm{A} 1 \mathrm{M}, \mathrm{B} 2 \mathrm{M}$ and $\mathrm{A} 2 \mathrm{M}$ and pro-BNP, CRP and ferritin levels.

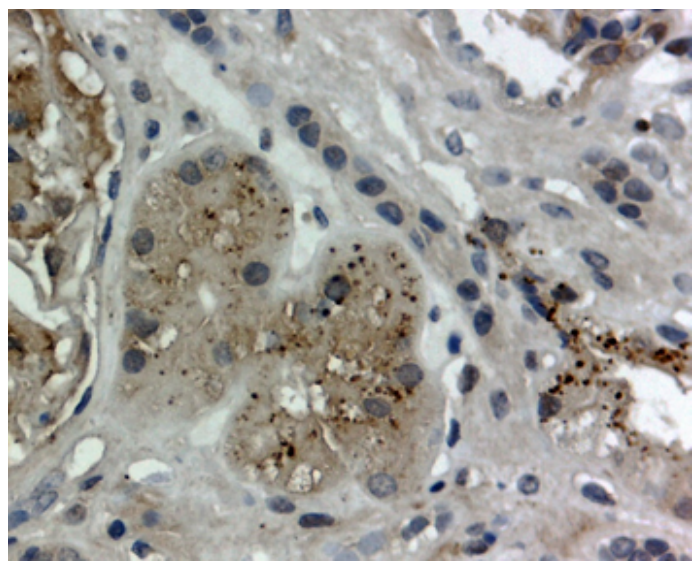

Figure 1: Anti-TTR fixation showed droplets accumulation in the renal proxima tubular cells, ATTR V30M-amyloidosis, immunoperoxidase technique, original magnification $\times 400$. 


\begin{tabular}{|c|c|c|}
\hline & Patients $(\mathrm{n}=30)$ & Asymptomatic gene carriers $(\mathrm{n}=11)$ \\
\hline uAlb $(\mathrm{mg} / \mathrm{g})$ & $1663.9 \pm 2019.9$ & $11.5 \pm 14.1$ \\
\hline $\mathrm{Cr}(\mathrm{mg} / \mathrm{dL})$ & $1.71 \pm 2.17$ & $0.72 \pm 0.14$ \\
\hline CysC $(\mathrm{mg} / \mathrm{dL})$ & $1.54 \pm 1.15$ & $0.66 \pm 0.12$ \\
\hline GFR $(\mathrm{mL} / \mathrm{min})$ & $76.9 \pm 52.6$ & $137.4 \pm 32.5$ \\
\hline CRP $(\mathrm{mg} / \mathrm{L})$ & $4.8 \pm 10.4$ & $3.8 \pm 5.3$ \\
\hline Ferritin $(\mathrm{ng} / \mathrm{mL})$ & $190 \pm 184$ & $171 \pm 228$ \\
\hline pro-BNP $(\mathrm{pg} / \mathrm{mL})$ & $1064 \pm 2165$ & $59 \pm 48$ \\
\hline
\end{tabular}

Values expressed as means \pm standard deviation

uAlb: albuminuria; Cr: serum creatinine; CysC: serum cystatin; GFR: glomerular filtration rate estimated by serum cystatin C; CRP: C- reactive protein; pro-BNP: pro-brain natriuretic peptide

Table 1: Study population laboratory parameters.

\begin{tabular}{|c|c|c|c|c|c|c|c|c|c|c|c|}
\hline Gender & Age & uAlb & $\mathrm{Cr}$ & CysC & GFR & B2M & $\mathrm{A} 1 \mathrm{M}$ & A2M & CRP & Ferritin & pro-BNP \\
\hline $\mathrm{M}$ & 63 & 21,1 & 0,96 & 0,87 & 91 & 28,7 & 8,5 & $<2,53$ & 1,42 & 278 & 34,2 \\
\hline $\mathrm{F}$ & 37 & 3,2 & 0,53 & 0,48 & 201 & 104 & $<5,16$ & $<2,41$ & 0,83 & 50 & 26,7 \\
\hline$M$ & 63 & 3,5 & 0,89 & 0,85 & 93 & 18,9 & $<5,96$ & $<2,41$ & 2,91 & 821 & 36,7 \\
\hline $\mathrm{F}$ & 28 & 4,6 & 0,82 & 0,62 & 141 & 16,1 & $<5,16$ & $<2,41$ & 3,37 & 60 & 25,7 \\
\hline $\mathrm{F}$ & 30 & 16,7 & 0,5 & 0,54 & 171 & 74,1 & $<5,96$ & $<2,41$ & 1,23 & 127 & 58,7 \\
\hline $\mathrm{F}$ & 33 & 2 & 0,72 & 0,65 & 134 & 121 & $<5,96$ & $<2,41$ & 18,39 & 90 & 42,6 \\
\hline $\mathrm{F}$ & 30 & 11 & 0,74 & 0,61 & 144 & 20,9 & $<5,16$ & $<2,41$ & 2,18 & 166 & 41 \\
\hline $\mathrm{F}$ & 27 & 0,9 & 0,78 & 0,64 & 136 & 91,3 & $<5,96$ & $<2,41$ & 1,58 & 49 & 71,3 \\
\hline $\mathrm{F}$ & 33 & 7,1 & 0,66 & 0,57 & 160 & 72 & 12 & 3,34 & 8,34 & 152 & 198,1 \\
\hline $\mathrm{F}$ & 63 & 7,4 & 0,7 & 0,73 & 114 & 43,7 & 8,86 & $<2,41$ & 0,76 & 37 & 56,9 \\
\hline $\mathrm{F}$ & 48 & 49,5 & 0,65 & 0,67 & 127 & 98,9 & 9,21 & $<2,47$ & 0,75 & 47 & 55,6 \\
\hline
\end{tabular}

M- male; F- female

uAlb: albuminuria $(\mathrm{mg} / \mathrm{g})$; Cr: serum creatinine $(\mathrm{mg} / \mathrm{dL})$; CysC: serum cystatin $(\mathrm{mg} / \mathrm{dL}) ;$ GFR: glomerular filtration rate estimated by serum cystatin C (mL/min); B2M: beta-2 microglobulin (ng/ml); A1M: alpha-1 microglobulin (mg/L); A2M: alpha-2 macroglobulin (mg/L); CRP: C- reactive protein (mg/L); ferritin (ng/mL); pro-BNP: pro-brain natriuretic peptide $(\mathrm{pg} / \mathrm{mL})$.

Table 2: Laboratory assessment in asymptomatic gene carriers.

\section{Discussion}

In current clinical practice, definitive diagnosis of ATTR nephropathy is based on renal biopsy findings. In our experience, however, the diagnosis can be reliably made in patients with albuminuria in the unequivocal presence of neuropathy. Conversely, we face two constraints. The first is that albuminuria is not a marker of tubulointerstitial damage. The second refers to the fact that this marker is absent in 10 percent of the patients who progress to ESRD [10].

Thus, improved methods for detect onset of kidney amyloid deposits, even before clinical disease, are needed to allow earlier treatment. This study is the first description of the contribution of urinary proteins, other than albumin, as non-invasive and costeffective markers to anticipate renal TTR amyloidosis.

A low content of protein in the urine, readily determinable, offers advantage over current biofluids widely used such as serum and plasma. The urine proteome represents the integrated product of glomerular filtration of plasma and protein shedding by cells of the proximal renal tubule, suggestive of both systemic and local contributions [11].

In our study, concentrations of all 3 urinary biomarkers increased progressively with decreasing GFR. One third of our patients presented a clear glomerular proteinuria, although significant tubular component was also observed. Urinary excretion of low-molecular proteins A1M and $\mathrm{B} 2 \mathrm{M}$, which are reliable indicators of tubular impairment, was present in 60 percent of patients. The occurrence of low molecular weight proteinuria, despite the absence of typical tubular syndrome, can be explained by the fact that megalin, a multiligand receptor expressed on the renal proximal tubules, functions as a specialized chaperone protein for internalization and degradation of a number of proteins, including A1M e B2M [12]. We speculate that the mechanism for low molecular weight proteinuria is not tubular damage but rather a saturation of the megalin-mediated endocytosis. So, the protein overload present in the lumen of the proximal tubule results in a combined low and high molecular weight proteinuria. We presume that urinary excretion of tubular proteins is related with severity of kidney injury and it is not a precocious marker.

The progressive dysfunction of the glomerular barrier leads to nonselective waste of high molecular weight proteins. Excretion of A2M is considered to be related with the severity of albuminuria. Unexpectedly, this correlation was not found.

Tencer et al. reported the proteinuria selectivity index as useful to describe changes of the glomerular permeability for macromolecules in glomerular diseases [13]. Proteins the size of A2M cannot normally pass the glomerular barrier. Based on a comparison of the clearance of high-molecular-weight proteins to that of albumin, the pattern of glomerular proteinuria may be described as either selective or nonselective. Early in the course of diabetic glomerular disease, selective proteinuria in both micro- and macroalbuminuric stages is observed. As the disease progresses, proteinuria becomes more nonselective and those with selective proteinuria tend to have a better outcome.

We consider that probably the low number of patients with pathological elimination of A2M did not allow a significant correlation.

However, the combined excretion of low and high molecular weight proteins was exclusively found in patients who progressed to ESRD.

Therefore, periodic screening of subclinical tubulopathy using 
Citation: Rocha A, Bravo F, Beirão I, Vizcaíno J, Oliveira JC, et al. (2014) Urinary Biomarkers for Kidney Disease in ATTR Amyloidosis. J Nephrol Ther 4: 181. doi:10.4172/2161-0959.1000181

Page 4 of 5

\begin{tabular}{|c|c|c|c|c|c|c|c|c|c|c|c|}
\hline Gender & Age & uAlb & $\mathrm{Cr}$ & CysC & GFR & B2M & $\mathrm{A} 1 \mathrm{M}$ & A2M & CRP & Ferritin & pro-BNP \\
\hline M & 64 & 5,9 & 1,27 & 1,25 & 56 & 4,29 & $<5,69$ & $<2,47$ & 3,39 & 158 & 256,6 \\
\hline $\mathrm{F}$ & 62 & 78,9 & 0,69 & 1,07 & 68 & 5,22 & 6,6 & $<2,47$ & 2,8 & 453 & 1643 \\
\hline$M$ & 59 & 1877,8 & 1,12 & 0,842 & 94 & 5,69 & 24,3 & 2,6 & 1,43 & 95 & 155,9 \\
\hline $\mathrm{F}$ & 52 & 1762,5 & 1,46 & 1,51 & 43 & 12,9 & 32,5 & 14,7 & 0,83 & 128 & 169,3 \\
\hline$M$ & 38 & 680,5 & 1,52 & 1,71 & 37 & 15,16 & 34,4 & $<2,53$ & 7,96 & 326 & 134 \\
\hline $\mathrm{F}$ & 55 & 4222,2 & 0,91 & 1,15 & 62 & 18,4 & 26,6 & 5,29 & 1,07 & 70 & 323,7 \\
\hline $\mathrm{F}$ & 32 & 1192,7 & 0,47 & 0,497 & 190 & 25,7 & 6,46 & $<2,41$ & 0,37 & 45 & 81,4 \\
\hline $\mathrm{F}$ & 44 & 671 & 0,65 & 0,843 & 94 & 25,7 & 25,7 & 3,6 & 0,39 & 143 & 131,8 \\
\hline $\mathrm{F}$ & 41 & 4187,1 & 0,54 & 0,96 & 79 & 28,2 & 9,16 & $<2,47$ & 0,14 & 13 & 91,6 \\
\hline $\mathrm{F}$ & 43 & 1298,4 & 0,63 & 1,07 & 68 & 31,2 & 41,2 & $<2,41$ & 53,46 & 38 & 594,9 \\
\hline M & 43 & 152,8 & 0,87 & 1,29 & 53 & 43,2 & 6,99 & $<2,41$ & 26,35 & 91 & \\
\hline $\mathrm{F}$ & 71 & 5103,3 & 4,56 & 3,76 & 13 & 46,13 & 123 & 17 & 1,87 & 490 & 2657 \\
\hline $\mathrm{F}$ & 34 & 8,4 & 0,76 & 0,75 & 110 & 55,3 & 6,29 & $<2,47$ & 4 & 57 & 196 \\
\hline $\mathrm{F}$ & 69 & 676 & 0,78 & 1,33 & 51 & 59,7 & 8,22 & $<2,47$ & 4,05 & 322 & 239,9 \\
\hline M & 50 & 67,9 & 0,76 & 0,63 & 138 & 59,9 & 10,2 & $<2,47$ & 2,6 & 553 & 16,6 \\
\hline $\mathrm{F}$ & 39 & 696,2 & 0,35 & 0,47 & 204 & 63 & 15,5 & $<2,47$ & 1,97 & 19 & 171 \\
\hline M & 32 & 3,7 & 0,87 & 0,69 & 122 & 74,3 & 6,61 & $<2,41$ & 0,51 & 18 & 16,3 \\
\hline$M$ & 56 & 83,2 & 0,81 & 0,66 & 130 & 84,7 & $<5,96$ & $<2,47$ & 3,45 & 110 & 81,7 \\
\hline $\mathrm{F}$ & 48 & 642,5 & 0,52 & 0,85 & 93 & 105 & 14,2 & $<2,41$ & 0,84 & 18 & 144,7 \\
\hline M & 40 & 577 & 2,94 & 2,91 & 18 & 117 & 47,6 & 2,5 & 0,19 & 45 & 1076 \\
\hline $\mathrm{F}$ & 39 & 6,2 & 0,63 & 0,64 & 135 & 119 & $<5,16$ & $<2,41$ & 0,27 & 122 & 134,5 \\
\hline $\mathrm{F}$ & 46 & 2,9 & 0,59 & 0,67 & 128 & 127 & 13,7 & 6,3 & 0,59 & 91 & 40,2 \\
\hline M & 36 & 790 & 0,58 & 0,79 & 103 & 173 & 16,5 & 4,35 & 2,2 & 288 & 174,8 \\
\hline $\mathrm{F}$ & 52 & 2381,7 & 1,43 & 2,86 & 18 & 297 & 9,34 & $<2,47$ & 10,32 & 244 & 4205 \\
\hline$M$ & 28 & 6,8 & 0,73 & 0,76 & 107 & 327 & 7,36 & $<2,47$ & 0,76 & 271 & 20,6 \\
\hline M & 64 & 1989 & 1,56 & 1,78 & 35 & 784 & 25,3 & 10 & 2,32 & 482 & 646,7 \\
\hline$M$ & 49 & 3193,3 & 1,98 & 2,95 & 18 & 6592 & 37,3 & 4,93 & 4,03 & 68 & 1712 \\
\hline $\mathrm{F}$ & 60 & 4728,7 & 6,17 & 3,19 & 16 & 26122 & 158 & 11,3 & 2,89 & 47 & 904,4 \\
\hline $\mathrm{F}$ & 69 & 7526,9 & 4,82 & 3,79 & 13 & 30627 & 98,5 & 4,85 & 1,89 & 204 & 4216 \\
\hline $\mathrm{F}$ & 68 & 5303,8 & 10,45 & 4,65 & 10 & 71105 & 34,8 & 89,8 & 0,68 & 691 & 10616 \\
\hline
\end{tabular}

M- male; F- female

uAlb: albuminuria (mg/g); Cr: serum creatinine (mg/dL); CysC: serum cystatin (mg/dL); GFR: glomerular filtration rate estimated by serum cystatin C (mL/min); B2M: beta-2 microglobulin (ng/ml); A1M: alpha-1 microglobulin (mg/L); A2M: alpha-2 macroglobulin (mg/L); CRP: C- reactive protein (mg/L); ferritin (ng/mL); pro-BNP: pro-brain natriuretic peptide $(\mathrm{pg} / \mathrm{mL})$

Table 3: Laboratory assessment in patients.

\begin{tabular}{|c|c|c|c|c|c|c|c|c|}
\hline & \multicolumn{2}{|c|}{ A1M } & \multicolumn{2}{|c|}{ A1M/cr } & \multicolumn{2}{c|}{ B2M } & \multicolumn{2}{c|}{ B2M/cr } \\
\hline Variables & $\mathrm{R}$ & $\mathrm{P}$ Value & $\mathrm{R}$ & $\mathrm{P}$ Value & $\mathrm{R}$ & $\mathrm{P}$ Value & $\mathrm{R}$ & $\mathrm{P}$ Value \\
\hline uAlb & 0.68 & $<0.01$ & 0.79 & $<0.001$ & 0.71 & $<0.01$ & 0.66 & $<0.01$ \\
\hline Cr & 0.57 & $<0.05$ & 0.71 & $<0.01$ & 0.74 & $<0.001$ & 0.69 & $<0.01$ \\
\hline CysC & 0.70 & $<0.001$ & 0.76 & $<0.001$ & 0.65 & $<0.01$ & 0.58 & $<0.01$ \\
\hline
\end{tabular}

uAlb: albuminuria; Cr: serum creatinine; CysC: serum cystatin

Table 4: Correlations between alpha 1-microglobulin (A1M) and beta-2 microglobulin (B2M).

these urinary biomarkers appears to be a simple and non-invasive means of identifying ATTR patients at risk of kidney disease, including impeding decline in kidney function.

Vyssouli et al. in a study involving 1445 nondiabetic patients revealed that urinary $\mathrm{A} 1 \mathrm{M}$ is independently associated with circulating acute phase proteins in patients with newly diagnosed hypertension. They concluded that urinary A1M may reflect the overall inflammatory status in patients with newly diagnosed hypertension, beyond its value as a marker of renal function [14]. In order to exclude the variation associated with inflammatory markers we evaluated CRP and ferritin. None of the individuals presented abnormal values. We did not find a correlation between A1M and these inflammatory proteins.

Cardiomyopathy is another well-known complication in FAP.
Considering that pro-BNP appears to be a sensitive marker for heart complications and proved valuable for follow-up purposes [15], we decided to search for a correlation between cardiac and kidney biomarkers. Nonetheless, no significant relation was found for this sample.

It must be highlighted that our study design has some limitations, such as the small size of the sample and the lack of a gold standard method to evaluate GFR. Additionally, we only had single measurements of $\mathrm{B} 2 \mathrm{M}, \mathrm{A} 1 \mathrm{M}, \mathrm{A} 2 \mathrm{M}, \mathrm{Cys} \mathrm{C}$, and creatinine, and these measurements are known to vary within participants.

Actually, an encouraging source of molecular markers for renal dysfunction and structural injury is urinary exosomes, nanovesicles released by renal epithelial cells including glomerular podocytes, renal 
tubule cells and the cells lining the ureter and bladder [16]. When combined with mass spectrometry and other proteomics techniques, urinary exosomes provide an opportunity to study proteins that were once either difficult or impossible to reach. For amyloidosis a first approach was designed in light chain amyloidosis [17].

However, it should be noted the fact that several proteins were evaluated together in the same population.

It is likely that a combination of biomarkers will be required for assessing disease detection and future response to a treatment. In conclusion, the use of urinary low and high molecular weight proteins, like $\mathrm{A} 1 \mathrm{M}, \mathrm{B} 2 \mathrm{M}$ and $\mathrm{A} 2 \mathrm{M}$, represented useful markers to estimate injury severity and monitoring the progression of renal lesion in ATTR V30M. The design of clinical urinary proteomics studies may increase our understanding of renal involvement in ATTR in the near future.

\section{Conflict of Interest}

On behalf of all authors, the corresponding author states that there is no conflict of interest.

\section{References}

1. Wallace MR, Naylor SL, Kluve-Beckerman B, Long GL, McDonald L, et al (1985) Localization of the human prealbumin gene to chromosome 18. Biochem Biophys Res Commun 28; 129: 753-758.

2. Lobato L, Rocha A (2012) Transthyretin amyloidosis and the kidney. Clin J Am Soc Nephrol 7: 1337-1346.

3. Ericzon BG, Holmgren G, Lundgren E, Suhr OB (2000) New structura information and update on liver transplantation in transthyretin-associated amyloidosis. Report from the 4th International Symposium on Familial Amyloidotic Polyneuropathy and Other Transthyretin Related Disorders \& the 3rd International Workshop on Liver Transplantation in Familial Amyloid Polyneuropathy, Umeå Sweden, June 1999. Amyloid 7: 145-147.

4. Johnson SM, Connelly S, Fearns C, Powers ET, Kelly JW (2012) The transthyretin amyloidoses: from delineating the molecular mechanism of aggregation linked to pathology to a regulatory-agency-approved drug. J Mo Biol 421:185-203.

5. Adams D (2013) Recent advances in the treatment of familial amyloid polyneuropathy. Ther Adv Neurol Disord 6: 129-139.
6. Petrica L, Petrica M, Vlad A, Jianu DC, Gluhovschi, et al. (2011) Proximal tubule dysfunction is dissociated from endothelial dysfunction in normoalbuminuric patients with type 2 diabetes mellitus: a cross-sectional study. Nephron Clin Pract 118: 155-164.

7. Madureira Silva MV, Moscoso-Solorzano GT, Nishida SK, Mastroianni-Kirsztajn G (2012) Serum Beta 2-microglobulin/cystatin C index: A useful biomarker in lupus nephritis? Nephron Extra 2: 169-176.

8. Borth W (1992) Alpha2- macroglobulin, a multifunctional binding protein with targeting characteristics. FASEB J 6: 3345-3353

9. Larsson A, Malm J, Grubb A, Hansson LO (2004) Calculation of glomerula filtration rate expressed in $\mathrm{mL} / \mathrm{min}$ from plasma cystatin $C$ values in $\mathrm{mg} / \mathrm{L}$. Scand J Clin Lab Invest 64: 25-30.

10. Lobato L, Beirão I, Silva M, Bravo F, Silvestre F, et al. (2003) Familial ATTR amyloidosis: Microalbuminuria as a predictor of symptomatic disease and clinical nephropathy. Nephrol Dial Transplant 18: 532-538.

11. Nolen BM, Orlichenko LS, Marrangoni A, Velikokhatnaya L, Prosser D, et al. (2013) An extensive targeted proteomic analysis of disease-related protein biomarkers in urine from healthy donors. PLoS One 8: 63368.

12. Vinge L, Lees GE, Nielsen R, Kashtan CE, Bahr A, et al. (2010) The effect of progressive glomerular disease on megalin-mediated endocytosis in the kidney. Nephrol Dial Transplant 25: 2458-2467.

13. Tencer J, Torffvit O, Thysell H, Rippe B, Grubb A (1998) Proteinuria selectivity index based upon alpha 2-macroglobulin or IgM is superior to the IgG based index in differentiating glomerular diseases. Technical note. Kidney Int 54 2098-2105.

14. Vyssoulis GP, Tousoulis D, Antoniades C, Dimitrakopoulos S, Zervoudaki A, et al. (2007) Alpha-1 microglobulin as a new inflammatory marker in newly diagnosed hypertensive patients. Am J Hypertens 20: 1016-1021.

15. Suhr OB, Anan I, Backman C, Karlsson A, Lindqvist P, et al. (2008) Do troponin and B-natriuretic peptide detect cardiomyopathy in transthyretin amyloidosis? J Intern Med 263: 294-301.

16. Lv LL, Cao Y, Liu D, Xu M, Liu H, et al. (2013) Isolation and Quantification of MicroRNAs from Urinary Exosomes/Microvesicles for Biomarker Discovery. Int J Biol Sci 9: 1021-1031.

17. Ramirez-Alvarado M, Ward CJ, Huang BQ, Gong X, Hogan MC, et al. (2012) Differences in immunoglobulin light chain species found in urinary exosomes in light chain amyloidosis (Al). PLoS One 7: 38061. 